\title{
Beiges Rädchen, pinkes Rädchen, fertig ist die Politur!
}

Restaurationen auf Hochglanz bringen ganz ohne Polierpaste und in nur 2 Schritten? Möglich macht's das neue Polierräderset von 3M, das ab sofort in Deutsch-

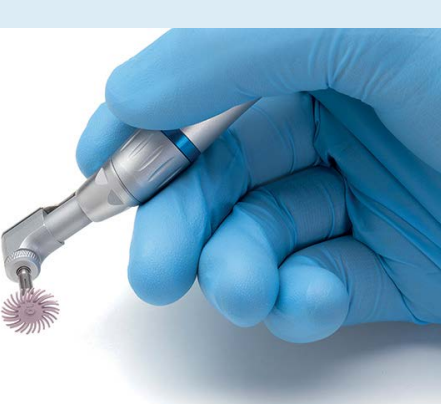
land, Österreich und der Schweiz erhältlich ist. Das SofLex Polierräderset besteht aus einem beigen, mit Aluminiumoxid beschichteten Rad für die Vorpolitur und einem rosafarbenen Diamantpolierrad für die Hochglanzpolitur. Nacheinander angewendet, erzeugen sie einen natürlichen Glanz. Die Räder lassen sich reinigen, desinfizieren und sterilisieren und sind somit wiederverwendbar. Dank einer hohen Flexibilität passen sich die Polierräder der Restaurationsoberfläche sehr gut an und gelangen in jeden Winkel, ohne die ursprüngliche Morphologie zu verändern.

Nach einer Pressemitteilung der

3M Deutschland GmbH, Seefeld 